
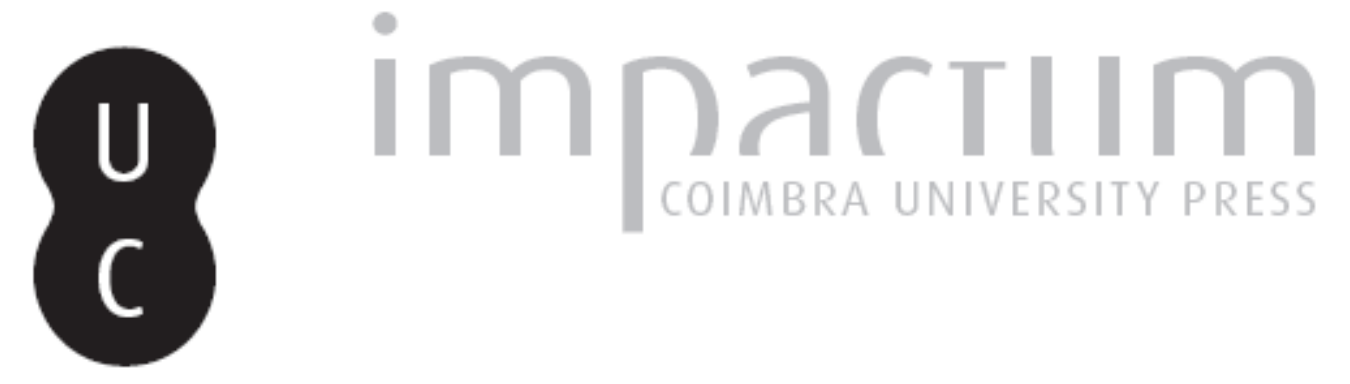
Como pensar na globalização? : contributo sociológico para um modelo de análise
interdisciplinar
Autor(es):
Silva, Augusto Santos

Publicado por: Imprensa da Universidade de Coimbra

URL persistente:

URI:http://hdl.handle.net/10316.2/39053

DOI:

DOI:http://dx.doi.org/10.14195/2183-203X_43_1

Accessed : $\quad$ 26-Apr-2023 09:18:35

A navegação consulta e descarregamento dos títulos inseridos nas Bibliotecas Digitais UC Digitalis, UC Pombalina e UC Impactum, pressupõem a aceitação plena e sem reservas dos Termos e Condições de Uso destas Bibliotecas Digitais, disponíveis em https://digitalis.uc.pt/pt-pt/termos.

Conforme exposto nos referidos Termos e Condições de Uso, o descarregamento de títulos de acesso restrito requer uma licença válida de autorização devendo o utilizador aceder ao(s) documento(s) a partir de um endereço de IP da instituição detentora da supramencionada licença.

Ao utilizador é apenas permitido o descarregamento para uso pessoal, pelo que o emprego do(s) título(s) descarregado(s) para outro fim, designadamente comercial, carece de autorização do respetivo autor ou editor da obra.

Na medida em que todas as obras da UC Digitalis se encontram protegidas pelo Código do Direito de Autor e Direitos Conexos e demais legislação aplicável, toda a cópia, parcial ou total, deste documento, nos casos em que é legalmente admitida, deverá conter ou fazer-se acompanhar por este aviso. 


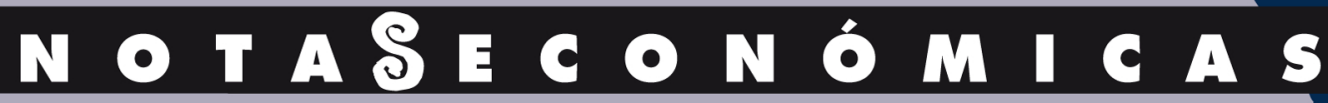

AUEUSTO SANTOS SILVA

FILIPE SIIVA / CARLOS CARREIRA
COMO PENSAR NA GLOBALIZAÇÃO? CONTRIBUTO SOCIOLOGGICO PARA UM MODELO DE ANÁLISE INTERDISCIPLINAR

THE ROLE OF FINANCIAL CONSTRAINTS IN THE SERVICES SECTQR: HOW DIFFERENT IS IT FROM MANUFACTURING?
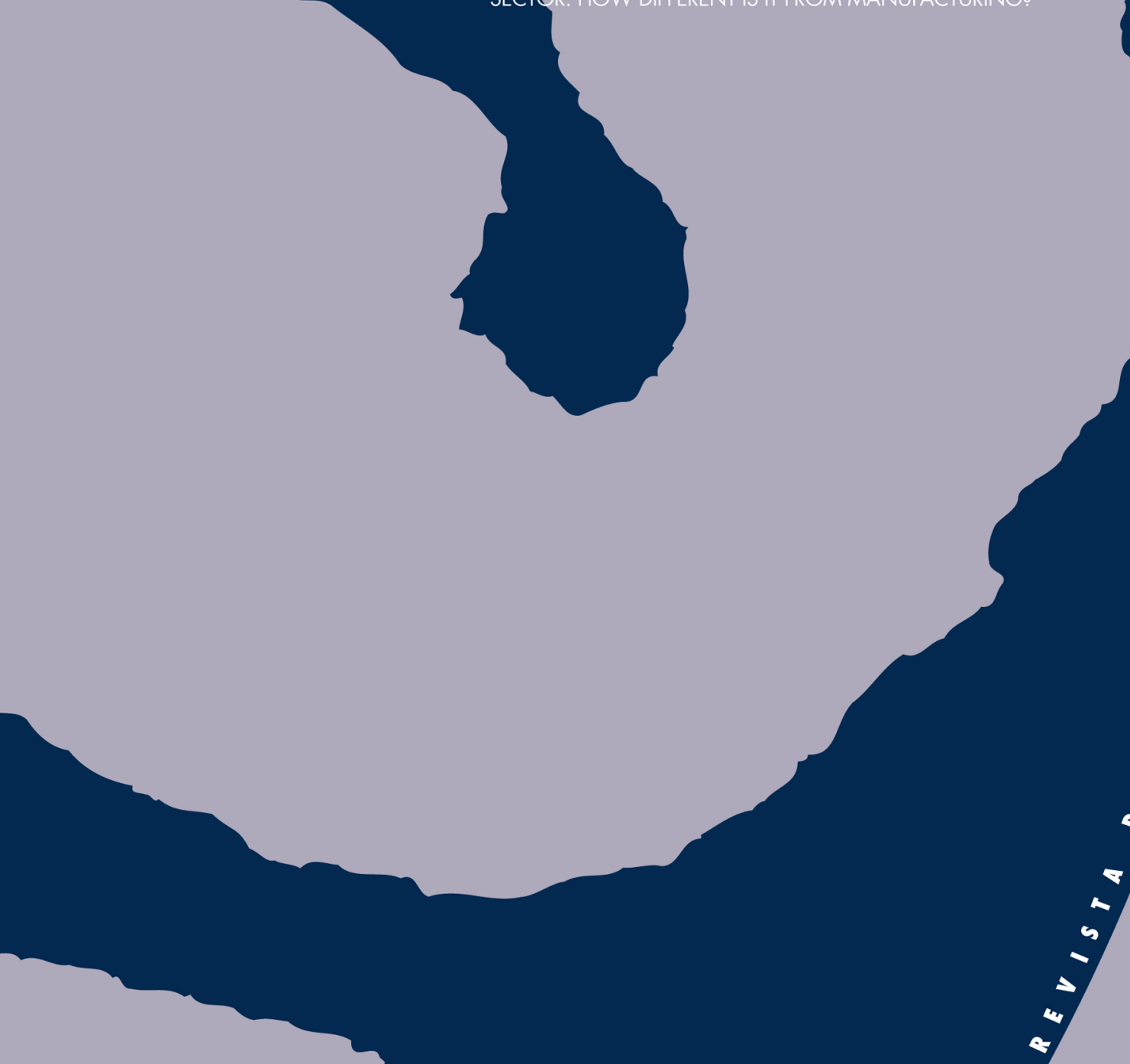

4

-

a

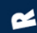

u

$\Rightarrow$

$-$

$z$

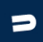

4

a

$a$

-

E

$\bullet$

2

○

$u$

w

4

$\theta$

4

$\theta$

8

0

$-$

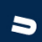

$u$

4

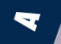




\section{Como Pensar na Globalização? Contributo Sociológico para um Modelo de Análise Interdisciplinar}

O artigo toma a globalização como um quadro para a análise dos processos económicos e sociais do nosso tempo. Começa pela crítica da ideologia da globalização como o triunfo inelutável da abertura e liberalização económica, contrapondo-Ihe uma abordagem que pretende ser mais analítica. Nos termos desta, a compressão do espaço-tempo, a integração e interdependência do sistema mundial e a sua heterogeneidade desenham um novo contexto para as instituições e os atores. Para compreendê-lo, precisamos de uma abordagem interdisciplinar, aproximando mais a economia, a sociologia e a ciência política, e colocando os factos em perspetiva histórica e geográfica. Assim podem ser exploradas novas perspetivas de análise, acrescentando-se valor ao conhecimento hoje disponível sobre a globalização.

\section{JEL Classification: Z10, Z13}

Keywords: globalization, economic policy, interdisciplinary
On considère la mondialisation comme un cadre d'analyse des processus économiques et sociaux contemporains. Ce qui est incompatible avec la représentation idéologique courante de la mondialisation en tant que l'indisputable triomphe de la libéralisation économique. Nous avons besoin d'une vision plus analytique, qui prête attention aux phénomènes de compression spatio-temporelle, intégration et interdépendance systémiques et hétérogénéité qui marquent le contexte de l'action humaine. Cette vision demande du travail interdisciplinaire : une approximation entre l'économie, la sociologie et la science politique ; une mise en perspective historique et géographique. Peut-être de nouvelles perspectives d'analyse seront ainsi ouvertes, ajoutant valeur aux connaissances maintenant disponibles sur la mondialisation.

How to Think about Globalization? A Sociological Contribution to an Interdisciplinary Analysis

Globalisation is a useful framework for the inquiry into contemporary social and economic processes. In order to do so, one has to oppose the current ideological representation of globalisation as the inevitable victory of economic liberalisation, and adopt a more analytical view. According to this view, the compression of spacetime, the systemic integration and interdependence and the heterogeneity of the world provide a new context for social institutions and agents. Full understanding of this context requires an interdisciplinary approach.

Economics has to come closer to sociology and political science, and the historical and geographical background must be taken into account. Thus, new analytical perspectives could be explored, adding value to the available knowledge on globalisation. 
Talvez concordemos todos na seguinte afirmação: é muito importante pensar no processo de globalização a partir da perspetiva das ciências sociais, tal é a relevância desse processo para a conformação do mundo de hoje e a ação nele. Mas ainda é possível esperar algo de novo nesse pensar, não estará tudo dito? Entendo que não, podendo acrescentar-se algum valor ao conjunto de estudos disponíveis. Não do ponto de vista da atualização e tratamento sistemático da informação: a quantidade e o ritmo de circulação de dados empíricos não se compadecem sequer com o tempo que demora a escrita, avaliação e publicação de um artigo numa revista científica. Mais vale acompanhar o trabalho de organizações internacionais como as Nações Unidas, a Organização para a Cooperação e Desenvolvimento Económico (OCDE), o Fundo Monetário Internacional (FMI) ou o Banco Mundial, ou de unidades credíveis de investigação e divulgação. Mas já do ponto de vista analítico não só me parece haver espaço para adição de conhecimento como necessidade de fazê-lo.

A questão é simples: como daremos conta do que está acontecendo à nossa volta e indica profundas transformações no espaço-tempo em que se inscrevem as estruturas económicas e sociais e nas relações que entretecem? Devemos indagar a razão de ser, o significado e o impacto de mudanças como estas. De acordo com o relatório de outono de 2015 do FMI (International Monetary Fund, 2015: 145), se medirmos o produto em paridades de poder de compra, a China é a maior economia, respondendo por $17 \%$ do produto mundial (e $11 \%$ das exportações). Os 12 países que assinaram, em outubro de 2015, o Tratado de Parceria Trans-Pacífico representam $40 \%$ do produto mundial e as negociações em curso entre os Estados Unidos (que lideraram a celebração daquele tratado) e a União Europeia, para um Tratado de Parceria Trans-Atlântico, envolvem cerca de metade do produto mundial. Em 2013, as Nações Unidas estimavam que China, Índia e Brasil, que representavam 10\% do produto mundial em 1950, pudessem vir a representar 40\% em 2050 (United Nations Development Programme, 2013: 13); entretanto, o crescimento dessas economias desacelerou e o Brasil entrou mesmo em recessão. Os três maiores centros de produção de filmes de cinema, em unidades físicas produzidas, localizam-se na Índia, nos Estados Unidos e na Nigéria. Anualmente, realizam-se mais de mil milhões de viagens internacionais de turismo. O Papa eleito em 1978 era polaco e, durante o seu pontificado de 27 anos, visitou oficialmente 129 países; sucedeu-lhe um alemão e a este um argentino: é a primeira vez que a Igreja Católica é chefiada por alguém do hemisfério sul. Estima-se que $90 \%$ dos 122 conflitos que ocorreram no planeta nas décadas de 1990 e 2000 tenham envolvido pelo menos um ator não estatal (Krause, 2012: 30). E o número de deslocados forçados por motivo de conflitos armados, perseguições e violação de direitos humanos ascendeu em 2014 a 59,5 milhões (United Nations High Comissioner for Refugees, 2015: 2).

Poderia multiplicar-se as ocorrências que assinalam transformações em curso na geoeconomia, na geopolítica, no tecido institucional e na vida das pessoas em todo o mundo. Precisamos de um quadro de análise para problematizar, observar e interpretar tais transformações; e o conceito de globalização é uma entrada possível. O geógrafo Olivier Dollfus (1997: 8) definiu-a como "a troca generalizada entre as diferentes partes do planeta, tornando-se então o espaço mundial o espaço de transação da humanidade". O economista David Throsby (2010: 3), como o processo através do qual "caem as barreiras ao movimento de fatores, especialmente o capital e o trabaIho, entre países e regiões; emerge um mercado global para muitas mercadorias, com oportunidades crescentes quer para empresas nacionais, quer para empresas multinacionais/transnacionais; e a internacionalização das comunicações, entre outros efeitos, leva à livre transmissão por todo o mundo de símbolos e mensagens". E a socióloga Saskia Sassen (2007: 14), distinguindo, como veremos, duas escalas pertinentes, global e subnacional, assinala na primeira "a formação de um mercado global para o capital, um regime comercial global e a internacionalização da produção industrial”. É clara a convergência, a partir de diferentes perspetivas disciplinares, assim como a operatoriedade destas primeiras definições para ir construindo um quadro de referência informado pelas ciências sociais. 
Para fazê-lo, porém, é imperioso questionar a representação da globalização que se tornou hegemónica, em muitas instituições internacionais e em círculos da opinião pública ocidental, a partir dos anos 90. Essa representação vai bastante mais longe do que a identificação e caraterização de um processo histórico nosso contemporâneo: propõe uma narrativa acerca dele; e pretende retirar um certo número de lições. Assim, a globalização deveria ser vista como uma espécie de fatalidade: uma evolução necessária, inerente às transformações tecnológicas e organizacionais nas economias mais pujantes e ao seu triunfo sobre o estatismo. Seria, além do mais, um progresso, quer em termos tecnológicos e económicos, quer em termos sociais; e não apenas face a etapas históricas anteriores como em comparação com situações e modelos alternativos coexistentes. O que demonstraria a razão de ser do chamado Consenso de Washington, ou seja, da defesa de políticas de liberalização do comércio internacional e do investimento estrangeiro, de desregulação económica e privatização de setores e funções públicas e de disciplina orçamental por imposição de austeridade na despesa pública e contenção do rendimento disponível. Essas políticas seriam (consoante as versões) as mais apropriadas ou as únicas possíveis no quadro da globalização, porque esta provocaria inelutavelmente a erosão de funções capitais do Estado nacional e eliminaria ou tornaria ineficientes as medidas de regulação política da economia. Por contraste, a globalização evidenciaria a exaustão do modelo europeu de crescimento e bem-estar, posto em prática no Pós-II Guerra e particularmente vibrante até às crises petrolíferas dos anos 70. A dinâmica económica estaria agora noutras paragens e, sobretudo, dependeria mais da abertura radical à internacionalização e da desvinculação entre as regras de mercado e as instituições sociais - isto é, de princípios muito diversos, senão frontalmente antagónicos, do antigo consenso europeu em torno da economia social de mercado e do Estado-Providência.

Esta narrativa tem, por si, a sedução da sistematicidade: tudo se explicaria em poucas proposições simples, capazes de dar conta de processos que se estendem por múltiplos lugares e décadas. A interpretação que propõe não deve ser liminarmente descartada, antes de qualquer exame. Mas, como muitos economistas têm mostrado (ver, entre outros, Amable, 2005; Stiglitz, 2007; Rodrik, 2012), são várias e sérias as anomalias explicativas que apresenta: designadamente, nem consegue dar conta das razões do sucesso de países da Ásia-Pacífico que apostaram precisamente num forte papel do Estado, nem das razões do insucesso de várias ações empreendidas na América Latina dos anos 90 por referência ao Consenso de Washington. As invisibilidades geradas também não são de somenos: por exemplo, o desenvolvimento da África Subsaariana. É difícil separar, na avaliação da situação europeia, o que é resultado de análise e o que é fruto de preconceito. E a proximidade da narrativa aos interesses próprios do capital financeiro e dos centros de poder do sistema mundial não lhe é um bom cartão-de-visita para uma indagação científica que teria de ser um pouco mais distanciada.

A minha sugestão, contudo, é que suspendamos um pouco o debate (inteiramente legítimo) a fazer no plano doutrinário e político e que nos concentremos no plano analítico (certamente influenciável e influenciado pelo primeiro, ainda assim distinto). De que é que realmente falamos quando falamos de globalização? Como podemos abordá-la? Como caraterizá-la? Como podemos enunciar de forma teoricamente fecunda e empiricamente verificável as questões que ela coloca, nas dimensões que lhe sejam relevantes? Em suma, que modelo de análise devemos construir a seu propósito?

Este é o objetivo do presente artigo. Na próxima secção, sugerir-se-á uma alternativa analítica às narrativas demasiado ideológicas sobre a globalização (favoráveis ou contrárias, para o caso não importa). Será uma alternativa fundada, por um lado, na aproximação interdisciplinar da economia, da sociologia e da ciência política e, por outro lado, na colocação do processo de globalização em perspetiva histórica e geográfica. Depois, na terceira secção do artigo, procurar-se-á mostrar como pensar a globalização como um processo multidimensional nos ajuda a identificar e compreender melhor algumas questões estruturais do sistema mundial contemporâneo. Assim se poderá, enfim, perceber que continua a fazer sentido pensar na globalização - não como mais uma poção mágica (Subrahmanyam, 2914: 53) que nos dispense de analisar realidades sociais que são muito complexas, dinâmicas e diversas, nem como uma lei ou uma causa capazes de explicar, por si sós, essas realidades, mas sim como um quadro de problematização e análise bem definido e com alcance heurístico e interpretativo. 
Atualmente, o mundo está mais pequeno, porque a fricção da distância, se bem que não tenha sido anulada, foi fortemente atenuada. Se há um elemento estruturante da globalização, é a compressão do espaço-tempo. Quatro fatores a explicam. O primeiro é a digitalização (ou "desmaterialização") da informação e dos seus processos de recolha, arquivo e transmissão. $O$ segundo é a revolução nos transportes e comunicações, que globaliza os itinerários de circulação de ideias, imagens, pessoas e bens. O terceiro é a redução dos custos de transação associados às trocas humanas, sejam elas o comércio, os serviços, a comunicação ou a relação de trabalho. Este fator é parcialmente consequência dos primeiros, assim como da erosão de barreiras administrativas ou estatutárias à circulação; e muda radicalmente as condições de acesso ao conjunto dos bens e oportunidades disponíveis. O quarto é a aceleração dos processos sociais, quer dizer, a diminuição do tempo necessário a percorrer o espaço e o aumento das atividades possíveis numa certa unidade de espaço-tempo. Este fator não só favorece a mobilidade dos agentes e a plasticidade das situações, como também introduz maior incerteza e imprevisibilidade na evolução das coisas.

Em segundo lugar, o mundo está mais integrado. Refiro-me à integração sistémica (Lockwood, 1964), quer dizer, ao nível de articulação das partes que o constituem num todo estruturado. A integração não é universal; e a circunstância de ela intensificar as ligações entre as partes articuladas acentua a exclusão das que se encontram à margem. É o que acontece hoje com várias sociedades da África Subsaariana, do Magrebe ou do Médio Oriente. Entre os mais poderosos vetores da integração sistémica do mundo encontram-se o comércio internacional, a organização e o investimento das empresas transnacionais e a ação das instituições económicas e políticas internacionais. Mas também as alianças e dinâmicas geoestratégicas do Pós-Guerra Fria, a entrada em cena de atores transnacionais não estatais e a mobilidade internacional de populações, incluindo a que é causada por guerras e outros conflitos. A integração faz-se a várias escalas, sendo particularmente relevante a regional, de que a União Europeia (e, dentro dela, a Zona Euro) é máximo exemplo, mas não único. Do cruzamento das várias escalas resulta, entretanto, a emergência de uma escala propriamente planetária. Razão continua, pois, a ter Anthony Giddens (1989: 519) quando diz que o traço específico do atual processo de globalização é que "o mundo se tornou, em importantes aspetos, um único sistema social'.

Em terceiro lugar, o mundo está mais interdependente. O que começa por ser, como bem notou Stiglitz (2007: 332), um efeito da integração, requerendo por sua vez a ação concertada de múltiplas entidades. Um número crescente de questões deixou de poder ser circunscrito às fronteiras de um país ou às condições da cooperação bilateral ou multilateral entre países. Ele exige uma abordagem supranacional (regional ou internacional), ou mesmo uma abordagem planetária, tornando impertinente a lógica de fronteira. É o que sucede com a questão ambiental, que foi a primeira e permanece sendo a grande questão global, porque diz respeito a um só território, o da ecúmena, e deve, portanto, como sustenta o geógrafo Christian Grataloup (2013: 266), ser tratada como um problema de ordenamento desse território, condição da sua sobrevivência. É o que acontece também em múltiplos outros domínios, desde a resposta às pandemias até à segurança militar. Mas a dependência recíproca dos atores do sistema mundial delimita também o quadro em que eles podem interagir estrategicamente: é ela própria uma fonte e uma restrição de poder (Nye Jr., 2011: 222-260).

Por último, o mundo continua a ser heterogéneo, se não está mais heterogéneo. O enunciado é menos assertivo do que os anteriores, visto que a diversidade interna de qualquer sistema social é um dado que não deixa de surpreender constantemente quem anda à procura de uniformidades. O mundo sempre foi muito heterogéneo. O ponto é que prossegue sendo, contrariamente a uma imagem muito espalhada da globalização como inexorável produtor de homogeneidade. Nem a compressão do espaço-tempo, nem a integração sistémica, nem o aumento da interdependência implicam, por si sós, uniformidade. Pelo contrário, acrescentam novos parâmetros de 
variação das situações e dos comportamentos dos atores, sejam eles grupos sociais, territórios, organizações, Estados ou redes. Claro que se alarga o espaço de inscrição e influência das hegemonias económicas, mediáticas ou político-militares: a globalização é também o contexto que permitiu que a transmissão televisiva do funeral da Princesa Diana, em 1997, fosse seguida por dois mil milhões de pessoas, ou que o computador portátil de uma grande marca se venda em qualquer canto do planeta. Mas não é menos verdade que a mobilidade, a velocidade e o âmbito da circulação, e a intensidade das trocas internacionalizam também - isto é, projetam sobre todo o sistema mundial - as múltiplas comunidades, condições e maneiras de ser que nos constituem, ao mesmo tempo que acentuam as assimetrias e desigualdades que as distinguem.

Onde apreender melhor estas dinâmicas atuais de compressão, integração, interdependência e diversificação? Dizer que em todas as dimensões é uma verdade, mas tautológica. Sugiro que olhemos a partir de cinco perspetivas muito promissoras. A primeira destaca os grandes movimentos populacionais de mobilidade territorial e recomposição societal - como as migrações e outras formas de mobilidade internacional, a multietnicidade e a multiculturalidade, as identidades múltiplas ou híbridas, as vinculações religiosas, éticas ou culturais que atravessam fronteiras e reconfiguram os espaços civilizacionais. A segunda perspetiva é a globalização das atividades económicas, atenta à globalização dos mercados de capitais e à correlativa financeirização da economia, assim como à expansão do comércio internacional e do investimento transnacional (Stiglitz, 2007; Rodrick, 2012). A terceira é a globalização do poder económico e da sua interação com as soberanias e as escolhas políticas, designável para sermos simples pela palavra regulação: as leis, os acordos e o direito internacional, os padrões de intervenção de grandes instituições económicas internacionais, as contrapartidas exigidas aos Estados para prover financiamento ou apoio ao desenvolvimento, e por aí fora (Stglitz, 2007). A quarta é a globalização das relações internacionais, na medida em que elas extravasam a lógica dita vestefaliana de um sistema de múltiplos Estados soberanos e de equilíbrio de poder entre o número restrito daqueles em condições de intervir como potências; e obrigam precisamente a agir no quadro e por relação com um nível mais geral e intenso de interdependência multilateral generalizada (Nye Jr., 2011). E a quinta será a globalização da segurança, no duplo sentido desta palavra: segurança das pessoas, bens e comunidades garantida por via de polícias, diplomacias e exércitos (security); e proteção das pessoas e comunidades face a riscos e ameaças incidentes sobre as suas condições de sobrevivência e bem-estar (safety). A segurança humana, o ambiente, a alimentação, a saúde, a cibersegurança, entre outras, entram aqui e fazem desta uma das dimensões mais propriamente globais (planetárias) da vida em comum (Burgess, 2012).

Não vejo como se possa cortar esta realidade em fatias, como se a globalização social não estivesse interligada com a económica ou esta com a das relações internacionais. Também não parece possível optar pela identificação demasiado apriorística e genérica de relações de causalidade entre estas dimensões, ou tentar dissolvê-las em sínteses demasiado apressadas e vazias. O que podemos e devemos fazer é convocar diferentes ciências sociais e suscitar uma cooperação interdisciplinar adequada e produtiva para uma abordagem compreensiva, quer dizer, abrangente e pluridimensional.

Concebo esta cooperação em duas formas lógicas, aliás requeridas pela natureza e complexidade do processo de globalização. Na primeira, trata-se de induzir uma maior aproximação recíproca entre a economia, a sociologia e a ciência política. Na segunda, trata-se de colocar a globalização em perspetiva histórica e geográfica. Ora, que condições é necessário cumprir para que estas abordagens frutifiquem?

O diálogo entre a economia, a sociologia e a ciência política obriga cada uma destas ciências a fazer a sua parte no esforço de convergência. Simplificando ao máximo, dir-se-á que se requer uma economia mais atenta à diversidade dos sistemas económicos e dos respetivos quadros institucionais (das empresas aos mercados e redes, da tecnologia e inovação às relações de trabalho, dos Estados aos territórios). O paradigma económico que melhor parece adequar-se ao estudo pluridimensional da globalização é, pois, o institucionalismo (cf. Amable, 2005: 41-100; Pereira, 2008: 11-106; Reis, 2009: 31-117). Quanto à sociologia, precisamos de uma sociologia 
empírica, menos obcecada com a interpelação crítica e com o proselitismo doutrinário e mais interessada na dilucidação das relações entre atores e estruturas nos diversos e distintos contextos societais. Esse é, afinal, o seu contributo próprio, parcial e incompleto como os demais, de modo que ela não pode reclamar uma vocação quase imperial de grande integradora das ciências sociais. A ciência política tem sabido incorporar, na análise das relações interestatais, princípios inspirados na teoria dos jogos e na modelização económica das decisões em contextos de restrição e de cooperação/competição entre atores. Importa é que, sem perder de vista a centralidade do Estado, saiba alargar a outras instâncias e atores essa análise dos jogos e equilíbrios de poder e do desenvolvimento da ação política (Nye Jr., 2011; Silva, 2000).

Evidentemente, em vários domínios, já estão consolidadas ou vão emergindo formas organizadas de convergência interdisciplinar em torno de problemáticas comuns: pense-se na sociologia económica, na economia política do desenvolvimento, nas relações internacionais ou nos estudos de segurança. A base, contudo, é esta triangulação absolutamente decisiva entre economia, sociologia e ciência política (Silva, 2015; ver, no mesmo sentido, Pereira, 2008).

Como ficou dito, a outra operação lógica reside na colocação da globalização em perspetiva histórica e geográfica. E talvez seja aí que se torne mais imperioso insistir, tal é a força sedutora das ideias fantasiosas sobre a absoluta novidade da globalização ou a sua "a-territorialidade".

Situar a globalização em perspetiva histórica significa perceber três ou quatro coisas fundamentais. Que a articulação de países, economias e regiões em sistemas supranacionais vem de muito longe no tempo, desde o mundo antigo das grandes civilizações do Mediterrâneo até ao Japão. Que a descoberta e a subsequente exploração da América conferiram um sentido radicalmente novo à lógica de um sistema mundial, porque ela passava a ser impensável fora da dialética entre o "Velho Mundo" (da Eurásia e do Magrebe) e o "Novo Mundo" (das Américas e do Atlântico Sul). Que a mundialização económica ligada ao desenvolvimento industrial conheceu uma primeira etapa ao longo do século XIX, marcada pela unipolaridade europeia (e particularmente britânica) e, depois, com a ascensão dos Estados Unidos na ordem internacional, nos inícios do século XX, uma segunda etapa, bipolar e transatlântica. A globalização económica de que hoje falamos carateriza-se, portanto, não só pela intensificação das trocas como sobretudo pelo reequilíbrio entre Atlântico e Pacífico - e talvez dela venha resultar o fecho histórico desse pequeno intervalo temporal, entre os fins do século XVIII e do século XX, em que a Europa tomou a dianteira do desenvolvimento tecnológico e económico mundial (sigo Grataloup, 2013). Que as vicissitudes da "Era dos Extremos" (Hobsbawm, 2008), entre 1914 e 1989 - o tempo de duas guerras mundiais, que foram também uma longa guerra civil europeia, e da Guerra Fria, com duas mundializações geopolíticas concorrentes, capitalista e comunista - mostram que a globalização é reversível, ou seja, que a história não é linear nem progride necessariamente no mesmo sentido (Grataloup, 2013: 223). E que os sistemas de regulação económica internacional postos em prática são diversos, podendo o quadro hoje vigente ser comparado, por exemplo, com o que foi constituído na sequência da II Guerra, baseado nos acordos de Bretton Woods (Rodrick, 2012: 69-76).

Não menos importante é a perspetiva geográfica, do espaço e do território. A globalização não significa a pura desterritorialização, mas sim um jogo complexo de desterritorialização e reterritorialização. Longe de se opor ao que é local, o global é um localismo globalizado, seja ele, como diz Boaventura de Sousa Santos (2015: 91), "a língua inglesa, Hollywood ou a comida rápida"; e o processo de globalização de um localismo representa ao mesmo tempo, muitas vezes, a localização do que já foi tomado como global (é, aliás, o que tantos apóstolos da globalização sem peias pretendem fazer ao keynesianismo ou ao modelo social europeu). Depois, exatamente porque tiram partido da possibilidade de jogar entre diferentes escalas territoriais, os protagonistas mais fortes da globalização, como as empresas multinacionais, rentabilizam eficazmente as vantagens associadas a economias de aglomeração: como Saskia Sassen (2007: 97-128) bem mostrou, a globalização económica é impensável sem considerar a importância estratégica das cidades globais. O território, enfim, como explica José Reis (2009: 235-236), não é apenas uma escala: é a dinâmica que aproxima cada economia da sua estrutura social e lhe confere densida- 
de e singularidade; é, pois, um gerador de polimorfismo estrutural - da diversidade que se mantém, se não cresce, com a globalização.

A triangulação disciplinar entre economia, sociologia e ciência política e a colocação dos factos em perspetiva histórica e geográfica parecem-me constituir o melhor quadro para analisar os contornos, sentido e consequências dessas dinâmicas hoje tão fortes de compressão espácio-temporal, integração sistémica, interdependência estrutural e diversificação. A Figura 1 procura representá-lo. Ele densifica e operacionaliza as definições provisórias de que partimos, no início deste artigo, e enfatizavam a nova escala das trocas, da mobilidade e da comunicação. Sem anular, o que é crucial, a enorme variedade das situações empíricas e o peso da espessura histórica na conformação e singularização de cada caso, ele permite avançar um pouco mais no esclarecimento e individualização do que, no sistema mundial de hoje, releva própria e especificamente da globalização - e a que, por conseguinte, deve ser reservada tal qualificação.

Figura 1. Um modelo de análise interdisciplinar do processo de globalização

\begin{tabular}{|c|c|c|}
\hline $\begin{array}{l}\text { Ciências sociais cujo diálogo } \\
\text { pode enriquecer a compreensão } \\
\text { da globalização como processo } \\
\text { social multidimensional: }\end{array}$ & $\begin{array}{l}\text { O valor acrescentado pela perspetiva } \\
\text { própria de cada uma das ciências: }\end{array}$ & $\begin{array}{l}\text { As caraterísticas distintivas do } \\
\text { atual processo de globalização: }\end{array}$ \\
\hline $\begin{array}{l}\text { 1.1. Uma economia inspirada } \\
\text { pelo institucionalismo: }\end{array}$ & $\begin{array}{l}\text { - O encaixe das economias nos } \\
\text { quadros institucionais; } \\
\text { - A diversidade dos sistemas } \\
\text { económicos. }\end{array}$ & \multirow{5}{*}{ 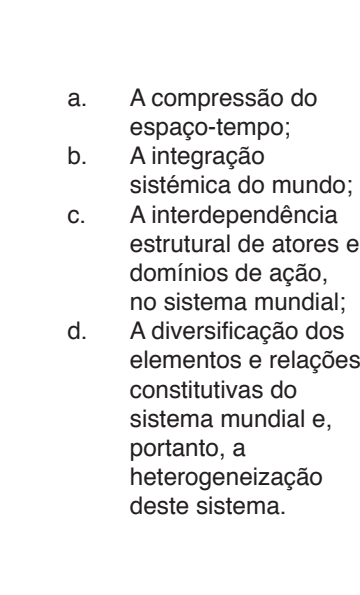 } \\
\hline 1.2. Uma sociologia empírica: & $\begin{array}{l}\text { - O jogo entre estrutura e ação; } \\
\text { - A articulação das múltiplas } \\
\text { dimensões (económicas, social, } \\
\text { política, institucional...). }\end{array}$ & \\
\hline $\begin{array}{l}\text { 1.3. Uma ciência política } \\
\text { economicamente inspirada: }\end{array}$ & $\begin{array}{l}\text { - As relações inter-estatais como jogos } \\
\text { de cooperação/competição entre } \\
\text { atores/potências; } \\
\text { - Os atores estatais e os atores não } \\
\text { estatais. }\end{array}$ & \\
\hline 1.4. A perspetiva histórica: & $\begin{array}{l}\text { - A geoistória do sistema mundial; } \\
\text { - A genealogia e a singularidade do } \\
\text { atual processo de globalização. }\end{array}$ & \\
\hline 1.5. A perspetiva geográfica: & $\begin{array}{l}\text { - A dialética entre local e global, } \\
\text { desterritorialização e } \\
\text { reterritorialização. }\end{array}$ & \\
\hline
\end{tabular}

As instituições sociais, políticas e económicas são múltiplas e diversas, porque se inscrevem em diferentes territórios e diacronias e combinam de diferentes maneiras regras e recursos. Ao contrário do que tantas vezes se escreve, a globalização não é o processo de reescalonamento pelo qual uma escala, a mundial, substitui e anula, ou torna irrelevante, as escalas subplanetárias. $\mathrm{O}$ clássico jogo de escalas do macro para o microfísico já não é o que mais conta. Para além desse reescalonamento, incontestável, há um fenómeno mais fundo, que é a multiplicação das escalas. "Multi-escalar" (Sassen, 2007: 43; Grataloup, 2013: 243): essa é verdadeiramente a nova e distinta natureza do sistema mundial, no quadro da globalização.

A globalização resulta de um desenvolvimento mais na escala internacional: o que se realiza e ocorre nessa escala, como circulação e troca entre nações, adquire uma tal dimensão e importância que transforma qualitativamente a estrutura do mundo. Foi e é o que se passa, designadamente, com a expansão do comércio internacional, com o aumento do volume e a diversificação das direções das migrações internacionais, ou com a reestruturação geopolítica induzida pelo fim do dualismo constitutivo da Guerra Fria. 
A globalização resulta também da estabilização e consolidação de relações entre economias e/ ou nações em entidades supranacionais, de âmbito regional (quer dizer, não planetário), com diferentes contornos institucionais (aliás, evolutivos), entidades que se acrescentam ou mesmo substituem às unidades nacionais em vários planos da ação coletiva. A União Europeia que saiu dos sucessivos alargamentos, da ênfase na dimensão política e da união monetária é um bom exemplo. Até porque permite perceber que não falamos apenas do nível institucional (a Comissão negoceia tratados com os Estados Unidos, em nome da União, e assim sucessivamente), mas também no plano do quotidiano e das escolhas sociais (por exemplo, em 2014, pela primeira vez na história da União, os grandes partidos europeus apresentaram às eleições candidatos a presidentes da Comissão e os governos respeitaram essa candidaturas e o seu desempenho eleitoral na indigitação do novo presidente da Comissão Europeia). Mas estas entidades regionais, supranacionais, que atuam na cena mundial por iniciativa e mandato próprio, não se reduzem a Bruxelas ou ao Eurogrupo. Basta olhar com atenção para o que passou com a Organização do Tratado do Atlântico Norte, para a passagem do G7 ao G8 e depois ao G20 ou para os muito interessantes jogos que decorrem hoje à nossa vista para tentar erguer ou impedir blocos regionais, no plano económico-político ou político-estratégico.

A globalização não é, contudo, apenas isto: um mundo mais integrado, entidades supranacionais mais relevantes e ativas. É ainda, crucialmente, a erosão da escala nacional (que era a base da soberania no mundo vestefaliano) por virtude das dinâmicas transnacionais - quer dizer, aquelas que ignoram ou subalternizam a ordem político-administrativa ou a delimitação nacional de um mercado. As empresas transnacionais são isso mesmo, e assim operam. Não existem no vazio, nem são apátridas; têm âncoras territoriais bastante fortes, com sobrerrepresentação do Atlântico Norte (anglo-americano). Mas podem tomar as suas decisões estratégicas, em matéria de financiamento, investimento, emprego, comercialização ou fiscalidade, à escala do mundo como tal, ou a subescalas regionais, variando a vinculação ao nacional ou ao supranacional consoante os seus interesses e objetivos. O capital financeiro (os bancos de investimento e grandes seguradoras, os fundos soberanos, os fundos de pensões e outros fundos de aplicações financeiras) e os mercados financeiros são claramente outras potentes forças transnacionais; como o são várias confissões religiosas de alcance mundial e as organizações de diverso tipo (do educativo e assistencial ao militar) que nelas se dizem inspirar, ou ainda, nos termos de Arjun Appadurai (2004) as "paisagens" mediáticas e étnico-culturais que se estruturam hoje transversalmente às estabelecidas divisões do mundo.

A globalização é, finalmente, a dinâmica de articulação transnacional de unidades e escalas subnacionais - como cidades, territórios ou lugares. As cidades globais são isto, cidades em que se inscrevem redes globais e que se ligam por redes globais; como o são muitas comunidades de diáspora, ou as organizações não-governamentais de ação local e referência e concertação global; como são os distritos económicos marshallianos, e outras formas de estruturação de redes de tecnologia, inovação e empreendedorismo, ou as praças financeiras, ou os centros de difusão, socialização, recrutamento ou mobilização espalhados pelo fundamentalismo.

O erro, que tanto tem apoucado o alcance da globalização como quadro de análise dos processos económicos e sociais, é pensar que estas quatro escalas se opõem umas às outras: que para pensar o internacional teríamos de subalternizar o supranacional, que para pensar o global devíamos declarar irrelevante o local, ou (a modalidade mais frequente do erro) que teríamos de musealizar o Estado para iluminar a economia-mundo. Estas escalas jogam entre si, e é essa lógica multi-escalar a que nos permite perceber melhor não só a globalização como, a partir dela, a história que se está fazendo - que estamos fazendo.

\section{Algumas perspetivas de desenvolvimento analítico}

Enriquecer o quadro de análise da globalização, por via da triangulação entre economia, sociologia e ciência política e da atenção às diacronias e aos territórios, abre novas perspetivas - isto é, aumenta o seu potencial heurístico, ou de descoberta. Procurarei ilustrá-lo identificando cinco dessas perspetivas. 
A. A revolução tecnológica na informação e comunicação e a revolução organizacional e comportamental que lhe está associada, permitindo a passagem para a "economia informacional" descrita por Manuel Castells (2002), são, desde os fins do século XX, forças motrizes da globalização. É evidente o seu papel na integração económica mundial e na gestão planetária das interdependências. A exploração dessa fronteira tecnológica, a sua combinação com a automação dos processos produtivos e a sua utilização sistemática na gestão organizacional e na estratégia empresarial junto de clientes e mercados, mudaram completamente a escala e o modo da atividade económica. O conhecimento (científico, tecnológico e social) constitui a base de um número crescente de atividades de produção e serviço e o seu recurso mais crítico. Nenhuma forma de ação humana está hoje fora do universo criado pela digitalização, a fusão entre dispositivos de comunicação e de transmissão de dados, a internet e as múltiplas redes de comunicação nela inscritas.

Ainda assim, um quadro mais largo de análise identifica outras dimensões não menos relevantes da sociedade da informação. Refiro-me, em particular, à reconstrução da forma social comunitária. Ela estava tradicionalmente centrada no interconhecimento direto, na copresença e na comunicação face a face, quer dizer, fisicamente localizada. Mas agora, na sociedade da informação, já não exige nem a copresença nem a colocalização, porque o seu espaço é virtual e a distância física deixou de ser impedimento para a comunicação interpessoal, ponto a ponto (Castells, 2004; Cardoso, 2006). Os lugares das novas comunidades digitais não são físicos; mas são lugares, quer dizer, são espaços habitados, com regras e recursos partilhados, proximidade e densidade relacional. As celebradas e celebráveis "redes sociais" constituem um exemplo, um entre vários. A globalização induzida pelas novas tecnologias e plataformas de informação e comunicação é também a globalização da intimidade, da interação pessoal, da pequena comunidade de iguais por relação a algum elo de ligação. Não é o fim, mas sim a transformação do local, da multiplicidade e diversidades dos lugares de pertença, identificação e interação das pessoas, grupos e organizações. A globalização das comunicações produz, ao mesmo tempo, um mundo único (uma única ecúmena comunicacional) e mais lugares dentro dele (mais oportunidades e formas de inscrever redes de relação e agrupamento).

B. Também não será preciso gastar muitos carateres para fazer compreender, com Ulrich Beck (2006), que a "sociedade de risco" desta nossa contemporaneidade é mundial. Isto é, que o risco endógeno ao nosso próprio desenvolvimento (o risco que resulta não de uma qualquer variável externa, mas que é produzido pela economia e a sociedade moderna industrial) é verdadeiramente uma questão global, no duplo sentido de planetária e transnacional.

Já valerá, porém, a pena explicitar três notas adicionais. A primeira assinala a complexidade e interligação das componentes ou dimensões de segurança (security e safety), que vão da integridade de territórios e do controlo de infraestruturas nacionais críticas (como aeroportos ou refinarias) à salvaguarda dos sistemas informáticos, à proteção dos dados pessoais ou a padrões de segurança alimentar ou saúde pública. A segunda aponta para a centralidade das questões de segurança, não apenas para o Estado de direito e a soberania política (o que toda a gente vê e vale por si mesmo), mas também para a economia mundializada: ponto especialmente delicado no que toca à segurança energética e às rotas de comércio internacional. A terceira nota indica a enorme incerteza introduzida pelo facto de um número crescente de ameaças à segurança, humana e coletiva, assumir a forma chamada não convencional e ser protagonizado por agentes não estatais, que não reconhecem nem praticam nenhuma das regras que arbitram os conflitos, incluindo as guerras. E disto só pode dar conta um modelo alargado de análise da globalização.

C. Em torno da relação entre o estatal e o não estatal se situa, aliás, outro dos contributos mais promissores que vejo neste alargamento. A narrativa enganosamente simples que é tão corrente acerca da globalização convida-nos a olhar para o "Estado-nação" como um facto do passado. A globalização seria precisamente a era pós-estatal e pós-nacional. Convirá, todavia, observar mais de perto e a partir de vários ângulos.

Por um lado, os Estados e governos têm sido partes ativas - e liderantes - do processo de globalização, quer no que ele favorece as dinâmicas de expansão económica quer no que ele obriga às 
mudanças regulatórias. São os Estados e os governos nacionais, e/ou as entidades supranacionais por eles constituídas, que negoceiam os tratados de liberalização do comércio, estabelecem as regras das uniões monetárias ou aprovam as contrapartidas políticas exigidas aos países que requerem ajuda externa pelas organizações que a oferecem, como o FMI. São decisões dos governos que "desnacionalizam" certos planos de decisão nacionais - delegando-os em entidades supranacionais - e "desestatizam" certos níveis de atuação estatal - entregando-os a autoridades regulatórias independentes ou concedendo-as a agentes privados (Sassen, 2007: 47-96), mesmo na área cujo monopólio era classicamente a própria razão de ser do Estado, a força militar e policial legítima. A globalização não se fez nem se faz "contra" ou "para além" dos Estados, é ativamente protagonizada pelos Estados (Santos, 2001), e nas posições expectáveis de protagonistas liderantes, quando antecipam benefícios, ou em contracorrente, quando sucede o inverso. É, aliás, isto que explica várias das assimetrias da globalização, sendo os Estados Unidos um caso paradigmático: tão defensores dela quando significa mundialização da finança, do comércio e do investimento, assim como a imposição a virtualmente todos desse localismo globalizado que é o quadro anglo-americano de regulação económica minimalista, quanto seus adversários quando o que está em jogo é a justiça penal internacional, o ambiente e as alterações climáticas, ou a cooperação para o desenvolvimento.

Por outro lado, aqui como noutras dimensões, a globalização significa também um novo impulso e escala para processos antigos ou locais. Um dos efeitos mais importantes da globalização não tem sido a internacionalização dos nacionalismos, em vez do seu desaparecimento (Smith, 2006: 200-204)? A revalorização do Estado e do soberanismo em tanta opinião pública? O renascer da oposição ao multilateralismo? E não é real a tensão entre, de uma banda, a erosão efetiva do poder regulatório do Estado nacional - e até da soberania face, por exemplo, aos mercados financeiros - e, da outra banda, a sua centralidade na organização da comunidade política, na salvaguarda dos direitos pessoais e na administração da justiça, e em áreas que podem parecer menos "materiais" mas não são menos críticas, como os sentimentos e identidades coletivas?

D. Não se pode, pois, na compreensão da globalização, seja ela económica ou social, elidir a dimensão e a questão do poder - e por isso é tão importante que dialoguem as ciências económica e política. Isto vale para o próprio núcleo duro da globalização económica, o triângulo constituído pela finança, o comércio e o investimento.

Não sugiro que se desvalorizem as outras dimensões e questões, sobre as quais existe literatura sólida e abundante, como, por exemplo, as seguintes. A absoluta novidade histórica da atual globalização, pelo volume e escala atingidos, e pela financeirização da economia. A heterogeneidade dos impactos sociais, económicos, políticos e ambientais, simultânea ou variavelmente positivos e negativos: basta, por exemplo, comparar os ganhos globais na redução da pobreza com a reprodução e acentuação da periferização de grande parte do continente africano. A deslocação da geoeconomia mundial para Oriente, em particular para a Ásia do Sul e Pacífico e a maior incerteza que rodeia o jogo entre a ligação transatlântica e a ligação transpacífica; sendo, evidentemente, claro para todos o que esta transformação já significou em termos de padrões de especialização produtiva, fatores de competitividade internacional e modos de regulação das relações laborais e dos sistemas de segurança social.

Ainda assim, o alargamento do modelo de análise tem, pelo menos, a virtude de destacar outras duas questões críticas: as assimetrias e desigualdades; a regulação pública. Só uma atenção focada nas relações de poder Ihes há de conferir a importância que justificam, corrigindo simultaneamente alguns dos lugares comuns mais difundidos pelas narrativas simplistas pró e antiglobalização (ver também Costa, 2012). A estrutura do comércio mundial não se tornou mais equilibrada: é profundamente assimétrica, tal como o seu quadro regulatório, como assimétrica é a relação de forças entre as grandes empresas transnacionais, de um lado e, do outro, os Estados, os fornecedores, as organizações sindicais e as demais instituições públicas locais que aquelas enfrentam (Stiglitz, 2007). Por muitos fatores diretamente económicos que possamos identificar para dar conta da competitividade internacional - como a gestão, a tecnologia ou o capital humano - a sua listagem não nos deve dispensar de reter também as relações de poder em jogo e o modo como a regulação pública as incorpora ou delas se distancia, criando outras relações. 
E. A estrutura do sistema mundial depende pois, crucialmente, quer do dinamismo das grandes forças tecnológicas e económicas de globalização - como as tecnologias de informação e comunicação e como o comércio, o investimento, a financeirização e a mobilidade dos fatores - quer da evolução das relações entre Estados e blocos de Estados, assim como dos sistemas de organização e regulação internacional que delas dependem e têm expressão na Organização Mundial do Comércio, no FMI ou no regime das patentes e no direito da propriedade intelectual. Mas depende também da ação de múltiplos outros protagonistas cuja escala é, ao mesmo tempo, subnacional $e$ transnacional - como as cidades e megalópoles globais (Sassen, 2007: 97-128; Dollfus, 1997: 25-32), as zonas económicas especiais ou os territórios inovadores, as empresas e redes de empresas, as organizações não governamentais e as entidades político-militares de natureza não estatal. Depende ainda de fatores como as migrações e outros movimentos populacionais, e dos seus efeitos no que toca à geografia mundial das etnicidades e das pertenças e identidades religiosas e culturais. É também por isto que essa estrutura é tão dinâmica e já hoje não inteiramente restituível pela distinção convencional entre centros e (semi)periferias económicas ou geopolíticas: porque a geografia das centralidades - instaladas, ascendentes ou declinantes - é muito mais plástica (Grataloup, 2013: 38-39) e porque do cruzamento das trajetórias entre central e periférico, local e global, consolidado e emergente, resultam mais complexidade e variabilidade.

Este processo é facilmente apercebível se considerarmos, como ilustração empírica, o jogo entre as indústrias culturais e as identidades culturais.

Do lado das primeiras, o cinema, a televisão, a imprensa de referência internacional, o turismo, o desporto, os espetáculos e gravações musicais, os megamuseus e o circuito das grandes exposições, a edição, constituem uma das mais poderosas forças da globalização (assim como um dos principais beneficiários). São evidentes as consequências do ponto de vista da acessibilidade planetária da informação por elas filtrada e transmitida, assim como da linguagem, do sistema de valores, imagens, pessoas e objetos icónicos, da ideologia e do modo de socialização e consumo que incorporam e potenciam. O sistema de estrelato, as supermarcas e o dispositivo informacional e comunicacional que pressupõem, são hoje realidades planetárias. Nesse sentido, o termo de "aldeia global" cunhado por Marshall McLuhan (e descontado o tom tribalista), não se tornou impertinente (McLuhan, 1964; McQuail, 2003: 217-242). As "massas" dos meios de comunicação e da cultura de massas equivalem virtualmente, em mais do que um segmento, à população mundial como um todo. A força hegemónica e o efeito homogeneizador da globalização são inquestionáveis.

Não são, todavia, os únicos elementos em ação. A globalização também favorece a afirmação mundial de novos centros e a difusão transnacional dos seus produtos; e esse policentrismo muito dinâmico - quer dizer, o movimento contínuo de descentramento e recentramento, de periferias que evoluem para novas centralidades e centralidades que se tornam por sua vez periféricas ou mesmos marginais - vê-se muito bem no campo das indústrias e mercados culturais (Crane, 1992; Featherstone, 1995; Cuéllar, 1996; Melo, 2002). Os centros produtores de cinema estão na Índia e na Nigéria como nos Estados Unidos, a mais vistosa arquitetura internacional faz-se nas metrópoles asiáticas, as telenovelas e o futebol latino-americano, a música pop sul-coreana ou as notícias da Al Jazeera atravessam fronteiras.

Policentrismo, portanto; mas não apenas. Porque a natureza multi-escalar do mundo globalizado também aqui se observa com particular nitidez. A escala de circulação e o efeito de volume permitem a afirmação global de nichos de produção, consumo e linguagem artística que, sem deixarem de ser minoritários ou subterrâneos e marginais face à corrente principal da indústria de cultura e lazer, se desenvolvem em circuitos transnacionais e assim tornam mais diversa e heterogénea a paisagem cultural global contemporânea: pensemos, por exemplo, nas músicas world e jazz, na arte contemporânea ou no cinema de autor.

É, pois, uma tensão entre centros e periferias, cânones e margens, hegemonias e alternativas, consolidação e reestruturação de instituições, que está em questão - e não apenas o efeito de homogeneização planetária de referências, valores e padrões de comportamento, cuja presença e impacto não se nega mas se deve relativizar. Acontece, entretanto, que as formas culturais tão 
maciçamente difundidas pela indústria e a distribuição planetária se confrontam com as identidades culturais dos diferentes grupos e populações, expressas nas línguas, no património, nas tradições, nas artes e criações, e nos modos de recebê-las e apropriá-las. As identidades não são dissolvidas pela globalização, porque não se dissolvem instantaneamente a história e a diversidade que apresentam as civilizações e culturas situadas espácio-temporalmente (Warnier, 1999). É, aliás, por isto que alguns contestam a relevância da globalização - que tomam por uniformização - em termos culturais. Maneira, a meu ver, pobre de compreender o problema, já que defendo ser a heterogeneidade, ela própria, um efeito da globalização. Primeiro, as identidades não são essências primordiais, são construções humanas que se formam, mudam e adaptam e, portanto, o confronto entre indústrias culturais e identidades culturais também produz diversidade. E, segundo, a globalização permite precisamente internacionalizar as alternativas, as ações contra-hegemónicas, os desafios que as culturas, as religiões e as representações identitárias coletivas Ihe colocam, usando para fazê-lo os meios que ela tornou possível.

Concluindo

A globalização não é um dado adquirido. É um processo histórico, não-linear e reversível como todos virtualmente são. Não é um acontecimento simples, cuja necessidade estaria inscrita inelutavelmente na evolução das coisas; mas sim um complexo dinâmico de condições, atores, ações e seus efeitos agregados. Não é o que explica, antes o que deve ser explicado. Mas existe e imprime uma cor própria ao mundo contemporâneo: mais integração, maior interdependência, múltiplas escalas.

Por isso é incontornável considerar a globalização, para poder pensar o mundo contemporâneo. Não sendo a súmula do nosso tempo, é uma perspetiva indispensável para examinar os múltiplos e contraditórios processos que fazem e mudam o nosso tempo. Pensar na globalização significa valorizar o contexto que ela representa para estes processos e assim contextualizar a sua investigação. Em vez de ser, pois, um ponto de chegada, é um ponto de partida para a análise das ciências sociais.

Contudo, se a análise se mantiver refém de ortodoxias monodisciplinares, não estará à altura da complexidade e multidimensionalidade dos processos que ocorrem no quadro da globalização. Melhor fará, portanto, em alargar também os seus próprios horizontes. Uma maior aproximação recíproca entre economia, sociologia e ciência política, de um lado, e a atenção deliberada aos eixos da história e da geografia, do outro, é uma via possível, e espero ter mostrado pertinente e produtiva, para tal alargamento.

\section{Referências bibliográficas}

Amable, B. (2005) Les Cinq Capitalismes: Diversité des Systèmes Économiques et Sociaux dans la Mondialisation, Paris, Seuil.

Appadurai, A. (2004 [1996]) Dimensões Culturais da Globalização: A Modernidade sem Peias (trad.), Lisboa, Teorema.

Beck, U. (2006 [1986]) La Société du Risque: Sur la Voie d'une Autre Modernité (trad.), Paris, Flammarion.

Burguess, J. P. (Ed.) (2012 [2010]) The Routledge Handbook of New Security Studies, (reed.), Londres, Routledge.

Cardoso, G. (2006) Os Media na Sociedade em Rede, Lisboa, Gulbenkian.

Castells, M. (2004 [2001]) A Galáxia Internet (trad.), Lisboa, Gulbenkian.

Castells, M. (2002 [1996]) A Era da Informação: Economia, Sociedade e Cultura [trad.], Lisboa,

Gulbenkian. 
Costa, A. F. (2012) Desigualdades Sociais Contemporâneas, Lisboa, Mundos Sociais.

Crane, D. (1992) The Production of Culture: Media and the Urban Arts, Newbury Park, Sage.

Cuéllar, J. P. (1996) Notre Diversité Créatrice: Rapport de la Commission Mondiale de la Culture et du Développement, Paris, UNESCO.

Dollfus, O. (1997) La Mondialisation, Paris, Presses de Sciences Po.

Featherstone, M. (1995) Undoing Culture: Globalization, Postmodernism and Identity, Londres, Sage.

Giddens, A. (1989) Sociology, Cambridge, Polity Press.

Grataloup, C. (2013 [2007]) Géohistoire de la Mondialisation: Le Temps Longue du Monde (reed.), Paris, Armand Colin.

Hobsbawm, E. (2008 [1994]) A Era dos Extremos: História Breve do Século XX, 1914-1991 (trad.), Lisboa, Presença.

International Monetary Fund (2105) World Economic Outlook: Adjusting to Lower Commodity Prices, Washington, IMF.

Krause, Keith (2012 [2010]) Instruments of Security: Small Arms and Contemporary Violence, in J. P. Burguess, The Routledge Handbook of New Security Studies (reed.), Londres, Routledge, 27-38.

Lockwood, D. (1964) Social Integration and System Integration, in G. K. Zollschan; W. Hirsch (Eds.), Explorations in Social Change, Londres, Routledge and Kegan Paul.

McLuhan, M. (1964) Understanding Media, Londres, Routledge and Kegan Paul.

McQuail, D. (2003 [1983]) Teoria da Comunicação de Massas (trad.), Lisboa, Gulbenkian.

Melo, A. (2002) Globalização Cultural, Lisboa, Quimera.

Nye Jr., J. S. (2011 [2000]) Compreender os Conflitos Internacionais: Uma Introdução à Teoria e à História (trad.), Lisboa, Gradiva.

Pereira, P. T. (2008) O Prisioneiro, o Amante e as Sereias: Instituições Económicas, Políticas e Democracia, Coimbra, Almedina.

Reis, J. (2009 [2007]) Ensaios de Economia Impura (2a ed.), Coimbra, Almedina.

Rodrik, D. (2012) The Globalization Paradox: Democracy and the Future of the World Economy, Nova lorque, W. W. Norton.

Santos, B. S. (2001) Os Processos de Globalização, in B. S. Santos Sousa (org.) Globalização: Fatalidade ou Utopia?, Porto, Afrontamento, 31-106.

Santos, B. S. (2015) Epistemologies of the South: Justice Against Epistemicide, Boulder, Paradigm.

Sassen, S. (2007) A Sociology of Globalization, Nova lorque, W. W. Norton.

Silva, A. S. (2000) La Acción Política: Un Ensayo de Teoría y Perspectiva, in R. Aguila et al., La política: Ensayos de Definición, Madrid, Sequitur, 77-116.

Silva, A. S. (2015) Global crisis: A comprehensive interdisciplinary contribute to the paradigm change, Review of Keynesian Economics, 3 (1), 63-76.

Smith, A. D. (2006 [2001]) Nacionalismo: Teoria, Ideologia, História (trad.), Lisboa, Teorema. Stgilitz, J. E. (2007 [2006] Tornar Eficaz a Globalização (trad.), Porto, Asa.

Subrahmanyam, S. (2014) Aux Origines de l'Histoire Globale, Paris, Collège de France/Fayard. Throsby, D. (2010) The Economics of Cultural Policy, Cambridge, Cambridge University Press. 
United Nations Development Programme (2013) Human Development Report 2013: The Rise of the South, Nova lorque, UNPD.

United Nations High Comissioner for Refugees (2015) World at War: UNHCR Global Trends. Forced displacement in 2104, Genebra, UNHCR.

Warnier, J.-P. (1999) La Mondialisation de la Culture, Paris, La Découverte. 